\title{
DEVELOPMENT OF A BIM ADOPTION IMPACT MAP
}

\author{
Ury Gurevich $^{1}$, and Rafael Sacks ${ }^{2}$
}

\begin{abstract}
Public construction procurement agencies pursue adoption of BIM in various ways, but they strive to set policies and take actions to achieve successful adoption. Success is measured by the overarching relationship between their BIM implementation and achievement of value for their clients and the occupants of the facilities built. Based on in-depth case studies of five large agencies subject to the UK Government BIM mandate, a hypothetical BIM Adoption Impact Map (BIM AIM) has been compiled. The map is a conceptual model of the myriad direct actions that form this relationship. In ongoing research, we aim to test the validity of each of the map's proposed action-impact connections, to detail their inputs, their decision parameters and their utility functions. The map will enable agencies to plan and monitor their BIM adoption processes by predicting how the actions they take bring value to the end users (occupants and clients) of their projects BIM. The research method requires development, testing and refining of the BIM AIM through field trials, surveys and case studies, development of a network modelling solution, and analysis of the model to reach a hypothetical final adoption map.
\end{abstract}

Keywords: Building Information Modeling, BIM Adoption, Organizational Change, Project outcomes, Social Impact.

\section{INTRODUCTION}

One of the main challenges facing large construction clients in adopting BIM is to achieve systematic and planned implementations rather than random, local and uncoordinated adoption by the various actors in the design and construction process. Uncoordinated adoption without leadership or regulation could lead to varying expectations and different levels of ability, thus diminishing the fulfilment of potential benefits for all organizations in the construction process. Many major clients, managers, designers, permit agencies and construction contractors are investing in guides, standards and other policy documents that aim to guide BIM adoption (Eastman et al. 2011). The large number of BIM policy documents (BuildingSmart 2016; Chae and Kang 2015; Cheng and Lu 2015) created by different construction organizations reflect the attempts to facilitate the ways that organizations will generate and use BIM processes.

However, the mechanisms and the effects of these intensive adoption efforts are not well understood. Technology adoption models from other domains, such as the broader Information Technology industry, are not directly applicable to the AEC domain. Models devised to measure the extent or depth of BIM adoption do not capture the impacts of the interim steps of adoption efforts.

The goal behind development of the BIM Adoption Impact MAP (the BIM AIM) was to compile a theoretical "cause and effect" model that lays out the relationships between the actions taken by the managers of typical public construction procurement agencies

1 PhD Student, Virtual Construction Lab, Technion - Israel Institute of Technology, ury.gurevich@gmail.com

2 Associate Professor, Faculty of Civil and Environmental Engineering, Technion - Israel Institute of Technology, Haifa, Israel, cvsacks@technion.ac.il 
and the actual impact those actions have on the depth and extent of BIM adoption. The BIM AIM can be used by clients, managers, designers, permit agencies and construction contractors to plan and to measure their actions to enhance the level of BIM adoption.

Compilation of the map was informed by the literature on BIM and by data from case studies of the BIM adoption efforts of five large UK public client construction procurement agencies: the Ministry of Justice (MoJ), Transport for London/London Underground (TFL), Highways England (HE), the UK Environment Agency (EA) and Defence Infrastructure Organization (DIO), all of which are subject to the pioneering UK Government BIM Mandate (Cabinet Office 2011).

The paper presents the BIM AIM, explains its use, and defines further research goals.

\section{BACKGROUND AND LITERATURE REVIEW}

Organizations that require usage of BIM should consider technology, processes, people (Ramakrishnan and Testani 2012), and information (Eastman et al. 2011; Gao and Fischer 2008) in any strategic effort to change business processes. In practice, where each organization adopts BIM with no common point of contact, business decisions prevent collaboration, and levels of knowledge and understanding of BIM diverge sharply. On the other hand, enabling collaboration, transparency and setting common goals can increase the probability that organizations will reap the benefits and achieve better results.

The growing number of published BIM documents - guides and standards - reflects the growing adoption efforts within construction client organizations from different types and levels. BuildingSmart (2016) reports 81 BIM such documents. Examples include the Department of Veterans Affairs (Tiejten 2010), USC (USC 2012), Senate Properties Finland (Senate Properties 2012) and Statsbygg Norway ("Statsbygg BIM Manual 1.2.1," 2013). Most of these organizations are public agencies (national, state or city level) or private companies (large-scale construction owners). The organizations publish BIM documents that reflect organizational needs regarding interoperability, the role of the BIM manager, collaboration modes, operation and maintenance requirements, BIM execution plans, simulation \& analysis, design fee structure changes, Integrated Project Delivery, and prequalification of designers (Sacks et al. 2015). The first seven topics are common in the guides created by different construction client organizations, though their content, specificity, frequency and level of resolution are different. The last three topics are less common but they are equally relevant for successful adoption process.

These documents explain to the service providers of the different organizations how they should use BIM to best effect for the client. Different methods have been proposed to measure the degree to which organizations fulfil requirements. One example is Succar's BIM Maturity Matrix $\left(\mathrm{BIm}^{3}\right.$ ) and Competency Sets (Succar et al. 2013) which enables measurement of the maturity of BIM in the following topics: software, hardware, network, leadership, infrastructure, human resources, products and services, contracts and regulations. This model covers design, contractor or supplier firms. However, there is still a lack of in-depth tools to guide owners how to adopt BIM.

Another effort that focused on BIM adoption was the BIM Acceptance Model (BAM) (Chae and Kang 2015). BAM defines the connections between external factors and the individual and organizational intent with respect to BIM adoption. BAM is mainly used for adoption within professional organizations such as design firms or contractors and is oriented to organization-specific needs. It does not consider the inter-organizational connections which might influence projects and their outcomes for clients and occupants. 


\section{RESEARCH GOALS}

The purpose of this work is to develop a model to describe the impacts of BIM adoption actions with a view to supporting public owners plan and control adoption of BIM so that it will have maximum impact on client value. Analysis of the ways in which these clients can leverage the data compiled in the BIM processes for their projects reveals the extent of the beneficial outcomes that can be expected for the projects' end-users. On the basis of assessment of these two aspects - adoption patterns and project outcomes - we hope to identify the right implementation characteristics and to compile a road-map for broad implementation within public construction procurement agencies, project managers, designers, permitting agencies, construction contractors, clients and occupants and to draw conclusions concerning the relationships between them.

In order to model the connections between the different actors (clients, managers, designers, regulatory agencies and construction contractors), a deep understanding of the adoption process for technologies in each one of these organization separately, and in the relationships among them, is essential. An initial adoption map was created after a series of interviews conducted with public construction owner organizations (Gurevich et al. 2016). The map (see Figure 1) facilitates study of BIM adoption efforts by focusing on the relationships between the depth and the nature of adoption on the one hand, and achievement of desired outcomes, on the other. The next step is to understand the actions to achieve BIM adoption within the organization, and to find the triggers and connections between the actions taken within the organizations on the other actors.

\section{METHOD}

Identifying the connections and relationships between the use of BIM and the effect on the performance of completed buildings is challenging. One option is to measure organizational adoption attempts and results over time: this is possible but requires collecting information from many projects over extended periods. Surveys commonly require significant resources, but may not reveal information with sufficient depth to properly reflect the adoption process or the building outcomes. For this reason, a positivistic approach was adopted: detailing the hypotheses from the theory and collection of empirical evidence through action research to prove the hypotheses. The duration of the measurement is often long (Lingard and Rowlinson 1998), measured in weeks or months, because the frequency of events, such as meetings or management decisions, is low and the number of observations needed takes time to accumulate. Although collection of the data is complex, due to the frequent and intensive observations that focus on managers' behaviour and decisions within different organizations, clarification of the mechanisms behind each link in the network will allow organizations that are willing to adopt BIM to predict the expected results from the actions taken by the organization. 


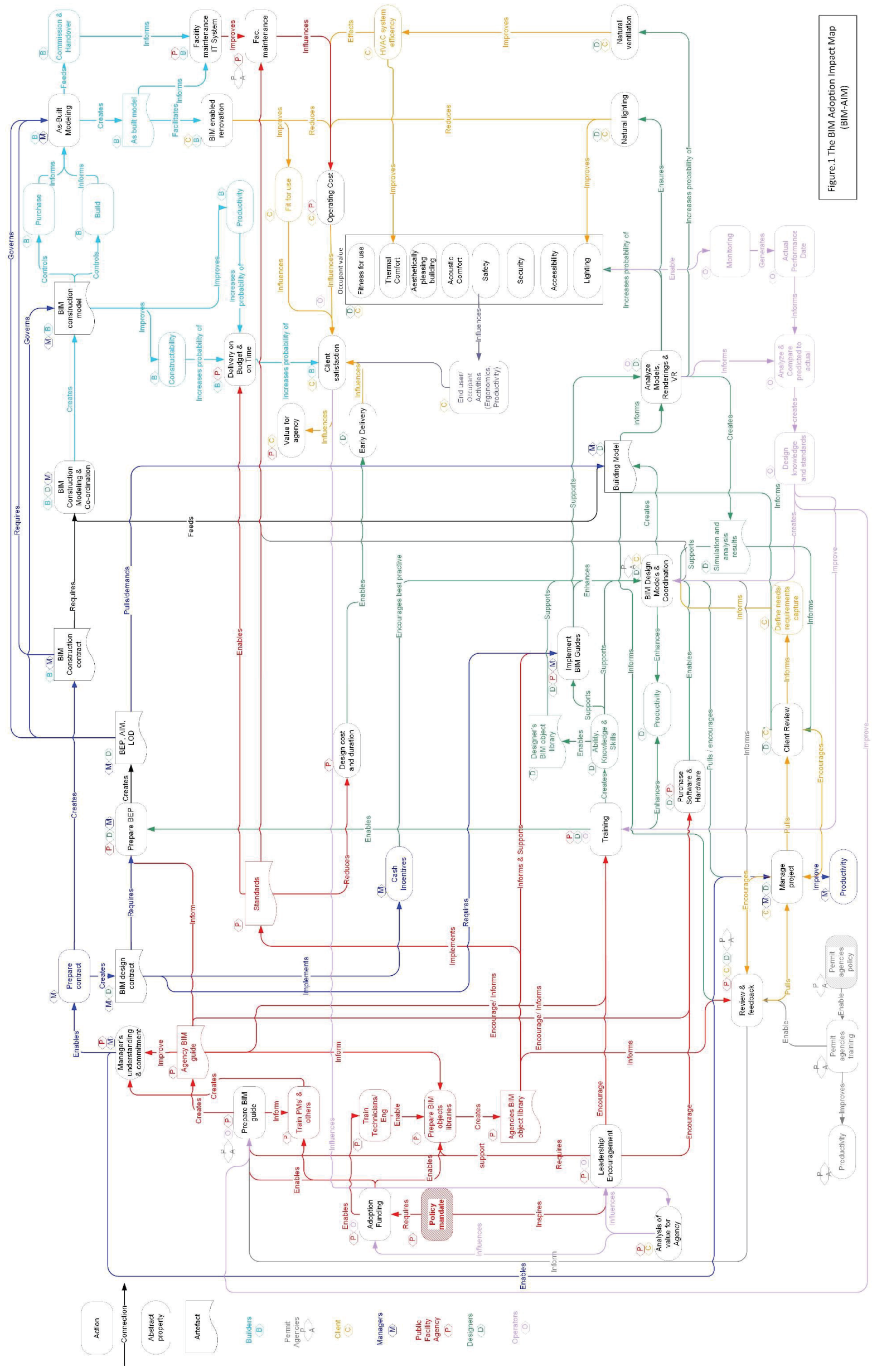


Creation of a model of this kind requires structural mapping of cause and effect (Gentner 1983). The model can be used for analysis of particular problems or as a planning tool. It consists of many hypothetical assumed relationships. Validation of each hypothesis, and resolving the most effective routes from agency inputs to BIM outcomes, is essential for compiling the model, although measuring the BIM AIM's actions is challenging due to the map's complexity. Use of IDEF0 (Dorador and Young 2000) (Integration DEFinition) was recognized as an appropriate tool for formal definition of the model. IDEF0, derived from a graphical language known as the structured analysis and design technique (SADT), models the decisions, actions and activities of a manufacturing organization or system in a structured graphical form. An IDEF0 model is based on a simple syntax. Inputs, controls, outputs and mechanisms (ICOMs) are all shown as arrows entering or exiting an activity box (Figure 2).

The IDEF0 model will be used to identify the bottlenecks, determine the flow and find the most effective routes, so that public clients can tailor their adoption actions to ensure best results from the end users' point of view. Figure 3 is an example of an IDEF0 definition for an action from the BIM AIM, "Prepare BIM Object Libraries". The input is the information about the required objects, the controls are leadership involvement and percent of funding, the outputs are the quality and quantity of BIM objects defined, and the mechanisms are training of BIM operators and the organization's BIM guide document.

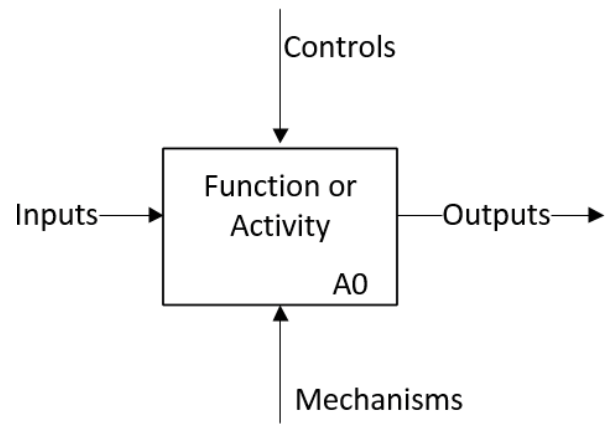

Figure 2. IDEF0 Syntax

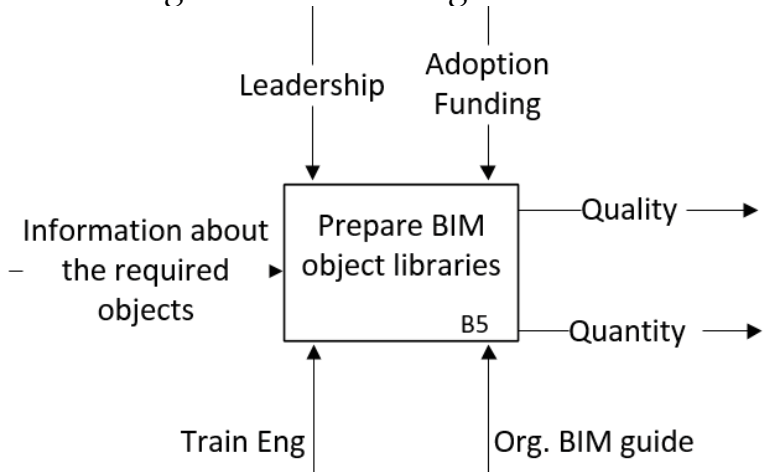

Figure 3. Example action shown in IDEF0

Each hypothetical action can be classified in one of the following four categories: Organization (management), Technology (design), Engineering and Economics. Each category requires different measurement methods. The actions are also time dependent, as they take place and have effect over time.

One of the main drawbacks in this type of research, using observations and particularly with action research, is that the presence or involvement of the researcher might affect the subjects and/or the processes. The Hawthorne effect (McCarney et al. 2007) defines a situation where the subjects are aware of the research, and this awareness influences their behaviours and thereby distorts the results. This phenomenon is more likely to appear in action research. Gold (1958) defined four levels of involvement of the researcher in the observation: pure participant, participant-observer, observer-participant and the pure observer. In this case the researcher functions as participant - observer, but the subjects are not aware that they are being observed, thus avoiding the Hawthorne effect. To avoid reducing the objectivity of measurements that could occur due to the deep involvement of the researcher, triangulation will be used for some of the hypotheses, enabling comparison of the observations to indirect measurements, and creating a better platform for understanding the different organizational decisions and their influences. 


\section{INTERMEDIATE OUTCOMES}

This section describes how the initial map was created and provides examples of the outcomes. The BIM Adoption Impact Map was created on the basis of five detailed case studies of government construction clients that are adopting BIM within the framework of the UK government BIM mandate. These case studies allowed comparison of the depth and nature of the adoption process against a theoretical 'best-practice' defined in part by the UK BIM task force guide. All five use the same BIM technology, and all have adopted fairly similar processes, but they differ in terms of preparation of their people and organizations. The case studies were investigated using in-depth interviews, questionnaires and case study write-up. Another major case study is being investigated using action research, in which the first author is playing a leading role in his own organization's process of BIM adoption.

The case studies were compiled following the first four of eight steps listed by Eisenhardt (1989). The protocol defined included a detailed questionnaire, face to face interviews of each agency's BIM adoption team with the research team, compilation of an interview summary and a case study draft using a transcript of the conversation and documents provided by the agency, review of the summary and the draft by the agency's representatives, and finally write-up of the case studies. The BIM AIM (Figure 1) was compiled from analysis of the data (step 5 of 8), but it also reflects the shaping of hypotheses (step 6 of 8 ) that is implied by each action-effect-result component of the adoption map.

All five were public construction organizations in the UK. The organizations studied were: Highways England (HE), Defence Infrastructure Organization (DIO), Environmental Agency (EA), Ministry of Justice (MOJ) and Transport for London/London Underground (TFL). A sixth organization was initially included in the sample but the data describing it proved to be insufficient. These organizations are large government construction owners, active in planning, design, execution, development and maintenance of building and infrastructure projects. The organizations' portfolios represent a diverse cross section of public project types, providing a broad perspective on BIM implementation. These five organizations were selected for study as leading examples due to their strong participation in the UK government BIM Task Force effort. They are all are subject to the government BIM Mandate.

The five case studies provided the opportunity to map the different processes, focusing on the relationships and the different actions that each one of the case studies organization have implemented and understood from the government affords regarding BIM adoption. The Map proposes hypothetical relationships among the clients, managers, designers, permit agencies and the construction contractors, reflecting the different paths of influence. These paths are composed of a series of links that reflect the results of an action or a state on the further actions of actors in the process.

The map incorporates a number of types of actions that an agency can take to influence the actors' adoption behaviour, in terms of people, process, technology and information. Leadership to increase motivation and training for all disciplines to improve knowledge and skills are both examples of people-related actions. Technology-related actions are most common and are well defined in different BIM documents (Kassem et al. 2014; Sacks et al. 2015). One of the more common examples is the BIM execution plans to define the technologies used in each project, selection of BIM software, collaboration systems, etc. Information-related actions are also common, such as definition of the LOD (Level of Detail), which can be very specific in some organizations. 
Additional possible actions, such as collecting feedback data from performance simulations and post-occupancy evaluations and comparing them to inform early-stage design using BIM, or defining new BIM terms and duties within the contracts, are less common and were mostly absent from the case studies informed initial compilation of the BIM-AIM.

\section{RESULTS, CONCLUSIONS AND FUTURE OBJECTIVES}

One of the major reasons for compiling a BIM AIM is to inform agencies that have not yet adopted BIM. The map serves as a tool to summarize the knowledge gained from the case studies, as a tool for comparative analysis across the case studies and it is also intended as a tool to guide other agencies in their BIM adoption efforts. Compiling the model requires a thorough understanding of the processes that agencies can use. The case study method and action research were selected due to their ability to provide a deeper understanding of the actions than could be obtained using surveys or other superficial methods (Fellows and Liu 2015).

The overall BIM adoption impact map includes all of the local adoption maps for the different actors (i.e. owner, design team, contractor, regulator, supervisor, project manager etc.). Each actor affects others and they all set together a common level of expectations. The initial BIM AIM has 110 actions, of which 14 were found to be strong across all five case studies. These 14 are all at critical intersections in the map, and all affect two or more actors (Gurevich et al. 2016). They include actions concerning the BIM execution plans, implementation of BIM Guides, analysis of models, management and leadership, and the obvious relationship between on-budget and on-schedule project delivery with client satisfaction.

It is well understood that there are several ways pursue BIM adoption. To be effective, owner organizations should pursue five common types of action: leadership (formulation of strategy), training, standardization (including preparation of BIM content libraries), preparation of appropriate contract clauses, and preparation of BIM guides (Gurevich et al. 2016). Yet not all of these are present in some of the case study organisations examined to date.

In its current form, the BIM AIM identifies the components and the sub components of the adoption process. Validation is ongoing, in an action research study of a large government procurement agency (in which the first author is playing a leading role in his own organization's adoption of BIM) and in two further case studies, all in countries other than the UK. The map potentially enables leaders to evaluate the organizational efforts, strengths, weaknesses and opportunities. Analysis of their process using the map mechanism can help leaders of different organizations to coordinate their BIM adoption efforts to ultimately improve design and production process.

Future work will focus on detailed modelling of the central actions and process in the BIM AIM through action research and supplementary methods. The inputs, outputs, controls and mechanisms of the actions will be represented using IDEF0 charts and their behaviour will be modelled. 


\section{REFERENCE}

BuildingSmart (2016). BIM Guide Project [WWW Document]. URL http://bimguides.vtreem.com/bin/view/BIMGuides/Guidelines (accessed 5.27.16).

Chae, L.S. and Kang, J. (2015). Understanding of Essential BIM Skills through BIM Guidelines, in: Tulio, Sulbaran (Ed.), 51st ASC Annual International Conference Proceedings, The Associated Schools Construction, April 22-25, 2015. p.8. Texas A\&M University.

Cheng, J.C. and Lu, Q. (2015). A review of the efforts and roles of the public sector for BIM adoption worldwide. J. Inf. Technol. Constr. 20, 442-478.

Dorador, J., Young, R.I. (2000). Application of IDEF0, IDEF3 and UML methodologies in the creation of information models. Int. J. Comput. Integr. Manuf. 13, 430-445.

Eastman, C.M., Teicholz, P., Sacks, R. and Liston, K. (2011). BIM Handbook: A Guide to Building Information Modeling of Owners, Managers, Designers, Engineers and Contractors, Second Edition. ed. John Wiley and Sons, Hoboken, NJ.

Eisenhardt, K.M. (1989). Building theories from case study research. Acad. Manage. Rev. 14, 532-550.

Fellows, R.F., Liu, A.M. (2015). Research methods for construction. John Wiley \& Sons.

Gentner, D. (1983). Structure-mapping: A theoretical framework for analogy. Cogn. Sci. 7, $155-170$.

Gold, R.L. (1958). Roles in sociological field observations. Soc. Forces 217-223.

Gurevich, U., Sacks, R. and Shrestha, P. (2016). Mapping Impacts of BIM Adoption Efforts by Large Public Owners on Occupant Value. BRI Under review, 37.

Kassem, M., Iqbal, N., Kelly, G., Lockley, S. and Dawood, N. (2014). Building information modelling: protocols for collaborative design processes. J. Inf. Technol. Constr. ITcon 19, 126-149.

Lingard, H. and Rowlinson, S. (1998). Behavior-based safety management in Hong Kong's construction industry. J. Safety Res. 28, 243-256.

McCarney, R., Warner, J., Iliffe, S., Van Haselen, R., Griffin, M. and Fisher, P. (2007). The Hawthorne Effect: a randomised, controlled trial. BMC Med. Res. Methodol. 7, 1.

Sacks, R., Gurevich, U. and Shrestha, P. (2015). Review of National Standards and Organizational Guides for BIM Adoption.

Statsbygg BIM Manual 1.2.1 (2013).

Succar, B., Sher, W. and Williams, A. (2013). An integrated approach to BIM competency assessment, acquisition and application. Autom. Constr. 35, 174-189. doi:10.1016/j.autcon.2013.05.016

Tiejten, R. (2010). The VA BIM guide. 